\title{
ВЛИЯНИЕ КЛИМАТА НА РАБОТУ ОЧИСТНЫХ СООРУЖЕНИЙ КАНАЛИЗАЦИИ Г. НОВОСИБИРСКА
}

\author{
Кругликова А. В.

\begin{abstract}
INFLUENCE OF CLIMATE ON THE OPERATION OF SEWAGE TREATMENT FACILITIES IN NOVOSIBIRSK
\end{abstract}

\author{
Kruglikova A. V.
}

\begin{abstract}
Аннотация
Введение. В настоящее время одной из основных проблем на функционирующих очистных сооружениях канализации является изменение качества очищенной сточной жидкости в холодный период года, что связано с охлаждением стоков по ходу очистки. К сожалению, на сегодняшний день данный вопрос практически не изучен. Методы. Исследования проводились на очистных сооружениях канализации г. Новосибирска с определением температуры сточной жидкости в первичных отстойниках, аэротенках и вторичных отстойниках, а также учитывались климатические параметры. Результаты. Проведен сбор статистических данных на функционирующих очистных сооружениях канализации г. Новосибирска (самый крупный объект за Уралом), обработаны данные методом линейной регрессии; полученные математические модели можно использовать для прогнозирования температуры сточной жидкости в открытых сооружениях в зависимости от температуры наружного воздуха. Заключение. Анализ математических моделей первичных отстойников, аэротенков и вторичных отстойников показал, что снижение температуры приводит к ухудшению качества сточной жидкости. Изучение математических моделей тепломассообмена между сточной жидкостью и окружающей средой позволило установить основные статьи потерь и поступления тепла: конвективный теплообмен, испарение с поверхности, потери тепла через ограждающие конструкции, излучение тепла с поверхности зеркала темного тела, унос и поступление тепла с воздухом, энергия солнца и тепло экзотермических реакций. На основании полученных результатов усовершенствован программный комплекс, который учитывает изменение температуры сточной жидкости в ходе ее очистки и может быть использован в помощь технологам очистных сооружений канализации.
\end{abstract}

Ключевые слова: первичные отстойники, нитрификатор-денитрификатор, вторичные отстойники, температура, сточная жидкость, климатические факторы.

\begin{abstract}
Introduction. Currently, changes in the quality of treated sewage in the cold period, which are associated with sewage cooling during treatment, represent one of the main problems at operating sewage treatment facilities. Unfortunately, to date, this issue almost has not been studied. Methods. The paper describes studies carried out at sewage treatment facilities in Novosibirsk. During those studies, the sewage temperature in primary and secondary tanks as well as aerotanks was determined, climatic parameters were taken into account. Results. Statistical data were collected at the operating sewage treatment facilities in Novosibirsk (the largest city beyond the Urals). The data were processed by linear regression method. The obtained mathematical models can be used to predict the sewage temperature at outdoor facilities depending on the outdoor temperature. Conclusion. The analysis of mathematical models of primary and secondary tanks as well as aerotanks showed that a decrease in temperature leads to sewage quality deterioration. The study of mathematical models of heat and mass transfer between the sewage and the environment allowed us to determine the main factors of heat loss and supply: convective heat exchange, evaporation from the surface, heat loss through the enclosing structures, heat radiation from the mirror surface of a black body, heat loss and supply with air, solar energy, and heat of exothermic reactions. Based on the results obtained, a software package has been improved that takes into account changes in the temperature of sewage during its treatment and can be used by production engineers of sewage treatment facilities.

Keywords: primary tanks, nitrifier-denitrifier, secondary tanks, temperature, sewage, climatic factors.
\end{abstract}

\section{Введение}

Новосибирск - крупнейший мегаполис за Уралом, находящийся в климатической зоне со следующими параметрами: продолжитель- ность теплого периода со среднесуточной температурой $>0{ }^{\circ} \mathrm{C}-188$ суток; продолжительность холодного периода со среднесуточной температурой $<0{ }^{\circ} \mathrm{C}-177$ суток; абсолютная 
минимальная температура воздуха — минус $50{ }^{\circ} \mathrm{C}$; абсолютная максимальная температура воздуха — $+37{ }^{\circ} \mathrm{C}$; температура воздуха наиболее холодной пятидневки минус $37{ }^{\circ} \mathrm{C}$; средняя максимальная температура воздуха наиболее теплого месяца — $+25,4{ }^{\circ} \mathrm{C}$; температура воздуха наиболее холодных суток минус $41{ }^{\circ} \mathrm{C}[7]$.

Мегаполис насчитывает более двух миллионов человек, имеет канализационные очистные сооружения (КОС) с общей производительность 1200 тысяч м³/сут (рис. 1).

КОС принимают стоки от жилой застройки, общественных зданий, промышленных предприятий городов Новосибирска, Бердска, Оби и от поселков Кольцово, Криводановка, Мочище, Краснообск и Пашино.

Сооружения были введены в эксплуатацию в 1970 году. Это самый поздний комплекс по очистке сточных вод среди построенных в Западной и Восточной Сибири. Он предусматривает классический вариант очистки стоков, включающий механическую и биологическую очистку, обработку и обезвоживание осадка. В состав сооружений механической очистки входят: приемная камера, здание решеток, аэрируемые песколовки, первичные радиальные отстойники с насосными станциями сырого осадка.

В состав узла биологической очистки входят реконструированные под нитрификатор-денитрификатор аэротенки четырехкоридорные, вторичные радиальные отстойники и насосно-воздуходувная станция.

Данные сооружения были выбраны в качестве объекта для изучения влияния климатических факторов на качество сточной жидкости по ходу ее очистки. Исследования на КОС г. Новосибирска интересны тем, что первичные отстойники, аэротенки и вторичные отстойники имеют большие открытые поверхности, а также объект находится в суровых климатических условиях с низкими температурами, сильными ветрами и переносами огромных масс снега.

Как показала практика эксплуатации многих КОС Западной и Восточной Сибири, в том числе

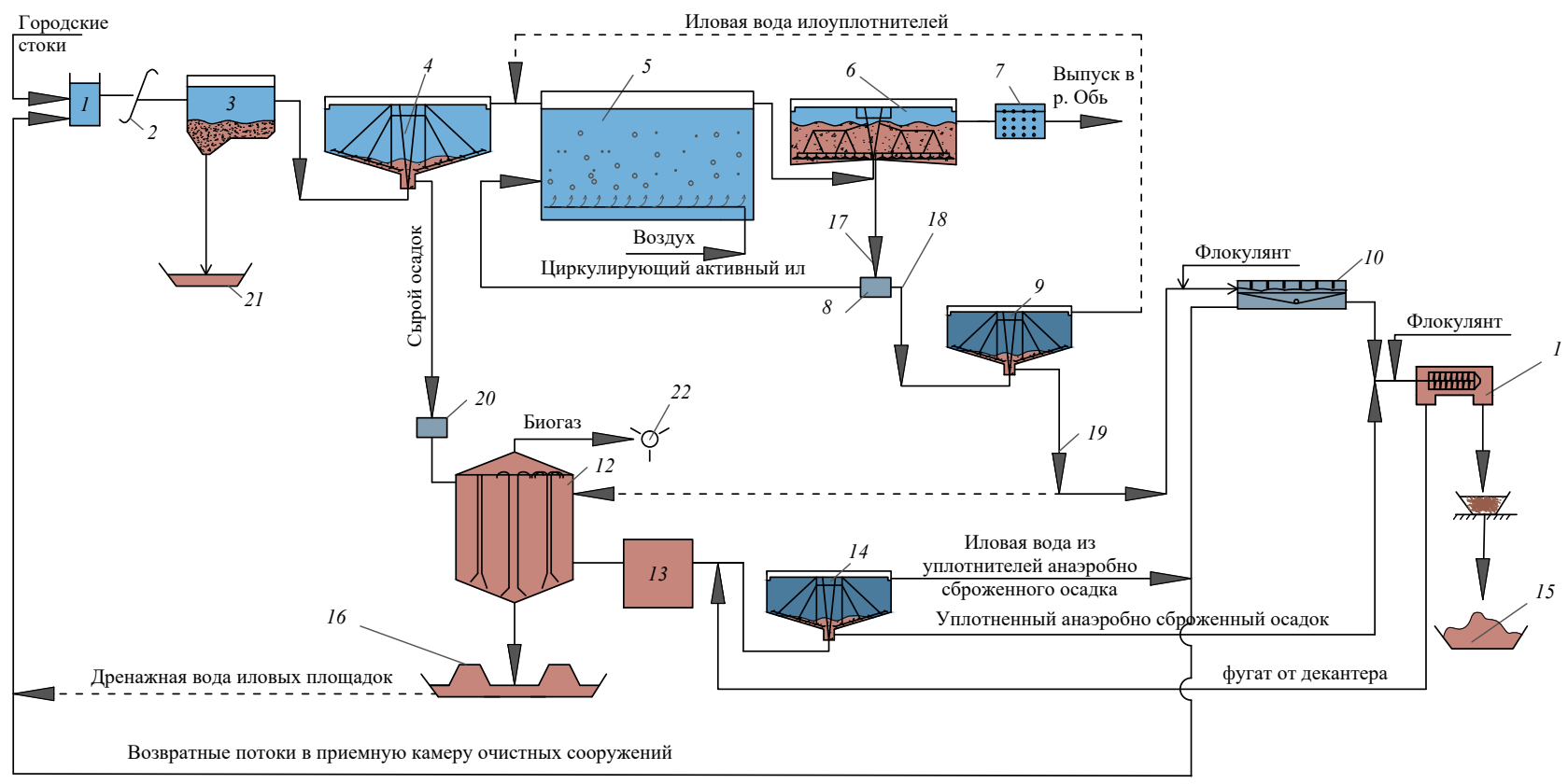

Рис. 1. Схема КОС г. Новосибирска:

1 - камера гашения напора; 2 - решетка; 3 - песколовка; 4 - радиальный первичный отстойник; 5 - аэротенк; 6 - вторичный радиальный отстойник; 7 - ультрафиолетовое обеззараживание; 8 - насосная станция вторичных отстойников; 9 - радиальный илоуплотнитель избыточного активного ила; 10 - ленточный сгуститель активного ила; 11 - декантер; 12 - метантенк; 13 - промывной резервуар анаэробно сброженного осадка; 14 - уплотнитель анаэробно сброженного осадка; 15 - площадка для хранения обезвоженного осадка; 16 - аварийные иловые площадки; 17 - избыточный активный ил; 18 - избыточный неуплотненный активный ил; 19 - уплотненный активный ил; 20 - насосная станция метантенков; 21 - песковые площадки; 22 - газовая свеча 
и в г. Новосибирске, при наступлении холодного периода ухудшается качество очищенных стоков из-за снижения температуры сточной жидкости на $1,5-5^{\circ} \mathrm{C}$. К сожалению, СНиП [4] при расчете очистных сооружений использует среднегодовую температуру сточной жидкости, а, как известно, она всегда выше средней за холодный период, месяц, а тем более за холодную пятидневку. Также в ряде статей отмечается, что сооружения биологической очистки, рассчитанные по существующим методикам, работают недостаточно эффективно $[11,12]$. Используя эти рекомендации уже заведомо закладывается некорректная температура стоков, которая, как отмечено в [3], влияет на результаты расчета.

Таким образом, некорректна температура в исходной сточной жидкости, более того, отсутствуют рекомендации по фактической температуре стоков в ходе ее очистки, т. е. в первичных отстойниках, аэротенках и вторичных отстойниках. При нагревании в сооружениях биологической очистки наблюдается острый дефицит кислорода из-за более низкой растворимости кислорода, что также приводит к ухудшению качества очистки $[15,18]$.

В связи с этим считаем, что для районов со специфическими климатическими условиями данная работа весьма актуальна.

Цель настоящей работы - усовершенствование программного комплекса, позволяющего анализировать, прогнозировать и оптимизировать эффективность работы объектов по очистке сточных вод в зависимости от показателей поступающих стоков и природно-климатических факторов.

Ранее была создана компьютерная модель [9], которая предназначена для анализа, прогнозирования и оптимизации конкретных функционирующих КОС, основными расчетными параметрами которой были расход и показатели сточной жидкости. Комплекс [1] был разработан в помощь эксплуатационному персоналу, он успешно решал задачи по выявлению возможных нарушений в работе объектов по очистке сточных вод в зависимости от изменения гидравлической нагрузки или нагрузки по загрязнениям, ухудшению технического состояния сооружений или отключению, включению дополнительного количества сооружений или оборудования, но не учитывал изменения температуры сточной жидкости в открытых сооружениях в ходе ее очистки. Вызвано это тем, что в существующей компьютерной программе не заложены математические модели, описывающие процессы тепломассообмена, протекающие в открытых сооружениях между сточной жидкостью и окружающей средой. В связи с этим возникла необходимость в усовершенствовании программного комплекса, который будет учитывать этот недостаток.

Задачами исследования являются: теоретическое изучение влияния температуры сточной жидкости на эффективность работы первичных отстойников, аэротенков и вторичных отстойников; изучение математических моделей теплотехнического расчета; сбор статистических данных на КОС г. Новосибирска; выбор математического метода обработки статистических данных; совершенствование существующего программного комплекса.

\section{Методы и материалы}

Для определения влияния климата на качество очистки сточной жидкости проводился сбор статистических данных на выбранном объекте исследования. Суть исследований заключалась в следующем: измерялась температура сточной жидкости в открытых сооружениях (первичные отстойники, аэротенки и вторичные отстойники), измерения проводились с помощью прибоpa TESTO-905 T1. Датчик прибора погружался в сточную жидкость выбранных сооружений и показывал температуру. Прибор TESTO-905 T1 обладает высокой точностью с измерительным диапазоном от $-50{ }^{\circ} \mathrm{C}$ до $+350{ }^{\circ} \mathrm{C}$ и погрешностью $0,1^{\circ} \mathrm{C}$. Позволяет производить быстро замеры температуры в течение 1-2 минут.

Вместе с этим фиксировались температура наружного воздуха, относительная влажность, атмосферное давление и скорость ветра с помощью прибора TESTO 410-2. Данные измерения проводились каждые два часа, чтобы проследить динамику изменения температуры стоков.

Для математической обработки полученных данных был выбран метод прямолинейной регрессии. Полученные уравнения линий регрессии позволяют прогнозировать значения переменных для каждого сооружения. Эти изменения впоследствии были проверены с помощью моделей 
тепломассообмена между сточной жидкостью в открытых сооружениях и окружающей средой.

Результаты исследования и обсуждение

Для изучения влияния температуры сточной жидкости на качество ее очистки были использованы известные к настоящему времени модели первичных отстойников [4-6, 17] и аэротенков $[8,13,14]$, а в расчете вторичных отстойников принималась откорректированная формула [4], в которую был добавлен коэффициент, который учитывает температуру сточной жидкости. Результаты приведены в табл. 1, 2 и 3.

Таким образом, как показали расчеты, изменение температуры сточной жидкости влияет на ее качество. Так, при температуре $15^{\circ} \mathrm{C}$, как рекомендует СНиП [4], эффект составляет 47,3\%, а вынос взвешенных веществ - 105,4 мг/л (см. табл. 1), БПК оолн очищенных стоков - 90 мг/л (см. табл. 2), вынос взвешенных веществ из вторичных отстойников - 10,7 мг/л (см. табл. 3), но при снижении температуры до $10{ }^{\circ} \mathrm{C}$ снижается эффект осветления в первичных отстойниках до 43,5 \% (см. табл. 1), снижение температуры приводит к увеличению БПК до 165 мг/л (см. табл. 2). В табл. 1 для примера приведены температура сточной жидкости и ее

Таблица 1

Данные по показателям очищаемой сточной жидкости при различной температуре стоков с учетом ее прохождения через первичные отстойники

\begin{tabular}{|c|c|c|c|c|c|}
\hline$T,{ }^{\circ} \mathrm{C}$ & $\alpha$ & $q_{\text {set, }} \mathrm{M}^{3} / \mathrm{ч}$ & $t_{\text {set, }}^{f} \mathrm{c}$ & $Э_{f}, \%$ & $C_{e x}, \mathrm{MГ} / л$ \\
\hline 10 & 1,3 & 2500 & 755 & 43,5 & 113 \\
\hline 15 & 1,15 & 2500 & 853 & 47,3 & 105,4 \\
\hline 15,25 & 1,14 & 2500 & 860 & 47,6 & 104,8 \\
\hline 20 & 1,0 & 2500 & 981 & 51,9 & 96,2 \\
\hline
\end{tabular}

Таблица 2

Данные по показателям очищаемой сточной жидкости при различной температуре стоков с учетом ее прохождения через аэротенки

\begin{tabular}{|c|c|c|c|c|c|}
\hline$T,{ }^{\circ} \mathrm{C}$ & $L_{c d p}, \mathrm{MГ/л}$ & $t_{a t}, \mathrm{\Psi}$ & $a_{i}$, г/л & $\rho_{f}, \mathrm{M \Gamma} /\left(\Gamma^{*} ч\right)$ & $L_{e x}, \mathrm{мГ/л}$ \\
\hline 10 & 315 & 9,45 & 2 & 11,3 & 165 \\
\hline 15 & 315 & 9,45 & 2 & 17 & 90 \\
\hline 15,05 & 315 & 9,45 & 2 & 17,05 & 88,7 \\
\hline 20 & 315 & 9,45 & 2 & 22,6 & 15 \\
\hline
\end{tabular}

качество, полученные при проведении сбора статистических данных.

В табл. 3 в графе $L_{e x}$ показаны данные, которые учитывают значения двух составляющих БПК

Сбор статистических данных производился в течение шести лет начиная с 2014 года и охватывает все сезоны года. К сожалению, сбор данных был проведен только для температуры сточной жидкости в дневное время суток, т. е. для наиболее благоприятного периода. Самый неблагоприятный период ночной, когда ниже температуры наружного воздуха и поступающих стоков и их нахождение в сооружениях.

В табл. 4 сведены данные замеров сточной жидкости в первичных отстойниках, аэротенках и вторичных отстойниках при температуре наружного воздуха от -33 до $+30{ }^{\circ} \mathrm{C}$, относительной влажности воздуха от 62 до $68 \%$, скорости ветра от 2,7 до 8 м/с и атмосферном давлении от 755 до 770 мм рт. ст.

Как видно из данных таблицы, при прохождении сточной жидкости основных сооружений в зимний период года при температуре $-33,0{ }^{\circ} \mathrm{C}$ температура стока снижается на $1,4^{\circ} \mathrm{C}$. В летний период года при температуре окружающего воздуха $+30{ }^{\circ} \mathrm{C}$ температура сточной жидкости прогревается на $1,5^{\circ} \mathrm{C}$.

Полученные уравнения линий регрессии для первичного отстойника, аэротенка и вторичного отстойника показаны на рис. 2. Согласно полученным данным математические модели позволяют определить температуру сточной жидкости в зависимости от температуры воздуха.

Для проверки правильности статистических данных были изучены математические модели тепломассообмена между сточной жидкостью

Таблица 3

Данные по показателям очищаемой сточной жидкости при различной температуре стоков с учетом ее прохождения через вторичные отстойники

\begin{tabular}{|c|c|c|c|c|}
\hline$T,{ }^{\circ} \mathrm{C}$ & $\alpha$ & $q_{s s a}, \mathrm{M}^{3} /\left(\mathrm{M}^{2} \mathrm{ч}\right)$ & $a_{t}, \mathrm{M \Gamma} / л$ & $L_{e x}, \mathrm{MГ} / л$ \\
\hline 10 & 1,3 & 1,19 & 14,6 & 175 \\
\hline 14,75 & 1,16 & 1,19 & 10,7 & 97,5 \\
\hline 15 & 1,15 & 1,19 & 10,6 & 96,1 \\
\hline 20 & 1,0 & 1,19 & 5,8 & 19 \\
\hline
\end{tabular}


Таблица 4

Результаты статистических данных, полученных на КОС г. Новосибирска

\begin{tabular}{|c|c|c|c|c|c|}
\hline $\begin{array}{l}\text { Время } \\
\text { замера }\end{array}$ & $\begin{array}{c}\text { Температура } \\
\text { наружного воздуха, }{ }^{\circ} \mathrm{C}\end{array}$ & $\begin{array}{c}\text { Скорость ветра } \\
\text { на высоте } 2 \text { м, м/с }\end{array}$ & $\begin{array}{c}\text { Относительная } \\
\text { влажность, \% }\end{array}$ & $\begin{array}{c}\text { Атмосферное } \\
\text { давление, мм рт. ст. }\end{array}$ & $\begin{array}{c}\text { Температура сточной } \\
\text { жидкости, }{ }^{\circ} \mathrm{C}\end{array}$ \\
\hline \multicolumn{6}{|c|}{ Точка на входе в первичный отстойник } \\
\hline $12-00$ & $-32,0-+26,20$ & $2,7-6$ & $66-65$ & $755-770$ & $15,1-25,1$ \\
\hline $14-00$ & $-33,0-+30,0$ & $2,9-7$ & $66-61$ & $755-768$ & $15,1-25,0$ \\
\hline $16-00$ & $-31,0-+30,0$ & $2,7-8$ & $62-68$ & $756-764$ & $15,4-25,2$ \\
\hline \multicolumn{6}{|c|}{ Точка на выходе из первичного отстойника } \\
\hline $12-00$ & $-32,0-+26,20$ & $2,7-6$ & $66-65$ & $755-770$ & $14,7-25,0$ \\
\hline $14-00$ & $-33,0-+30,0$ & $2,9-7$ & $66-61$ & $755-768$ & $14,6-25,0$ \\
\hline $16-00$ & $-31,0-+30,0$ & $2,7-8$ & $62-68$ & $756-764$ & $15,1-25,1$ \\
\hline \multicolumn{6}{|c|}{ Точка ввода циркулирующего активного ила } \\
\hline $12-00$ & $-32,0-+26,20$ & $2,7-6$ & $66-65$ & $755-770$ & $14,5-25,0$ \\
\hline $14-00$ & $-33,0-+30,0$ & $2,9-7$ & $66-61$ & $755-768$ & $14,5-25,0$ \\
\hline $16-00$ & $-31,0-+30,0$ & $2,7-8$ & $62-68$ & $756-764$ & $14,9-25,1$ \\
\hline \multicolumn{6}{|c|}{ Точка смешения с циркулирующем активным илом } \\
\hline $12-00$ & $-32,0-+26,20$ & $2,7-6$ & $66-65$ & $755-770$ & $14,3-25,1$ \\
\hline $14-00$ & $-33,0-+30,0$ & $2,9-7$ & $66-61$ & $755-768$ & $14,3-25,2$ \\
\hline $16-00$ & $-31,0-+30,0$ & $2,7-8$ & $62-68$ & $756-764$ & $14,8-25,2$ \\
\hline \multicolumn{6}{|c|}{ Точка на выходе из аэротенка } \\
\hline $12-00$ & $-32,0-+26,20$ & $2,7-6$ & $66-65$ & $755-770$ & $14,0-26,1$ \\
\hline $14-00$ & $-33,0-+30,0$ & $2,9-7$ & $66-61$ & $755-768$ & $14,1-26,3$ \\
\hline $16-00$ & $-31,0-+30,0$ & $2,7-8$ & $62-68$ & $756-764$ & $14,6-26,4$ \\
\hline \multicolumn{6}{|c|}{ Точка на выходе из вторичного отстойника } \\
\hline $12-00$ & $-32,0-+26,20$ & $2,7-6$ & $66-65$ & $755-770$ & $13,8-26,3$ \\
\hline $14-00$ & $-33,0-+30,0$ & $2,9-7$ & $66-61$ & $755-768$ & $13,7-26,5$ \\
\hline $16-00$ & $-31,0-+30,0$ & $2,7-8$ & $62-68$ & $756-764$ & $14,3-26,6$ \\
\hline
\end{tabular}

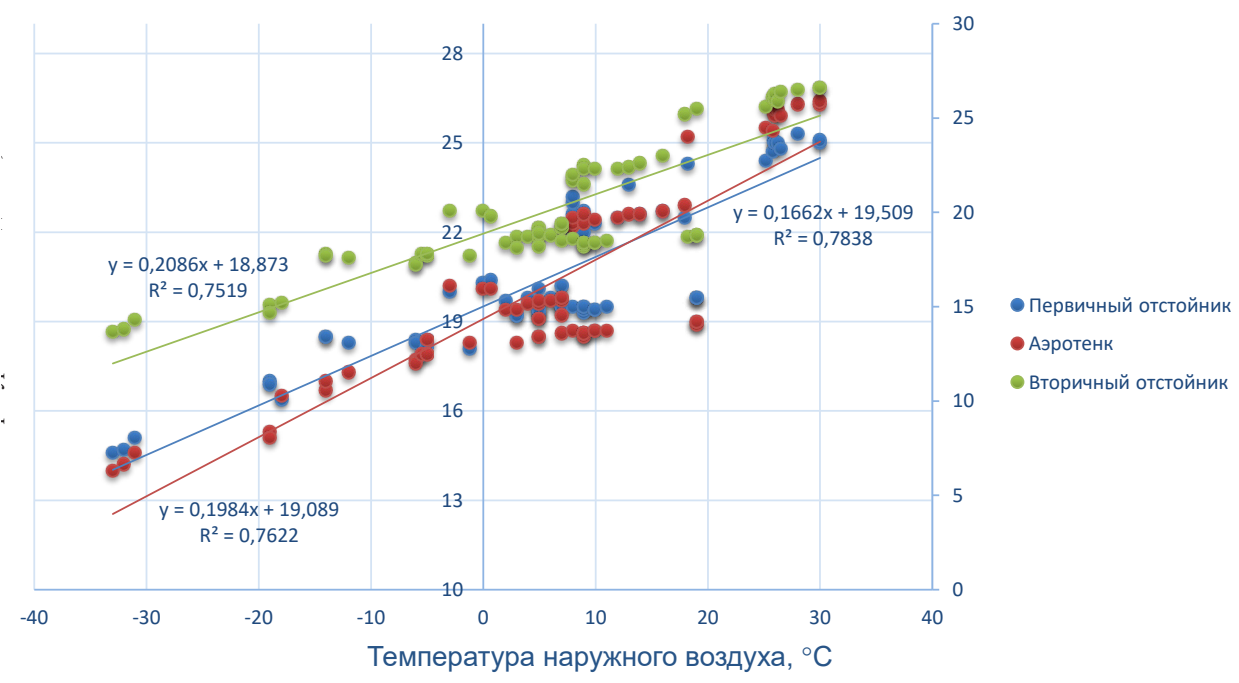

Рис. 2. Изменение температуры сточной жидкости в зависимости от изменения температуры наружного воздуха

открытых сооружений и температурой наружного воздуха. В данной технологической схеме открытыми сооружениями являются: песколовки и первичные отстойники, площадь открытой поверхности которых составляет 1688 м², именно эти сооружения теряют тепло в окружающую среду и получают тепло солнечной энергии. Так как продолжительность нахождения в песколов- 
ке составляет от одной до трех минут, то гипотетически можно утверждать, что как охлаждение, так и нагревание будут находиться в пределах погрешности прибора, используемого для замера температуры сточной жидкости. Поэтому при изучении влияния данное сооружение было исключено. В открытых первичных отстойниках основными статьями потерь тепла в холодный период года являются: конвективные теплообмен; испарение, расчет которого можно произвести как открытого бассейна в период бездействия [16]; потери через ограждающие конструкции и излучение тепла с поверхности зеркала темного тела.

В теплый период года в отстойниках тепло теряется на испарение, через стенки и днище, а прогревание сточной жидкости может происходить только за счет энергии солнца и конвективного теплообмена, который учитывает как естественную, так и вынужденную конвекцию $[2,10]$.

Открытая поверхность аэротенков составляет $4320 \mathrm{~m}^{2}$, вторичных отстойников - $1256 \mathrm{~m}^{2}$. В аэротенках основными статьями потерь тепла в холодный период года являются: конвективный теплообмен, испарение, потери тепла в грунт че- рез ограждающие конструкции, излучение тепла с поверхности темного тела, однако здесь добавляются еще потери тепла за счет возврата охлажденного активного ила из вторичных отстойников и унос тепла с воздухом. В летний период года потери тепла происходят за счет испарения, через ограждающие конструкции, а поступление тепла происходит так же, как в первичном отстойнике, - за счет энергии солнца и конвективного теплообмена, но еще за счет тепла, поступающего с воздухом в аэротенки и тепла экзотермических реакций. Во вторичных отстойниках статьи потерь и поступления тепла такие же, что и в первичных отстойниках.

Усовершенствование существующего программного комплекса проводилось путем включения в расчет этих изученных математических моделей.

Принципиальная схема программного комплекса приведена на рис. 3.

\section{Заключение}

Анализ математических моделей, используемых для расчета первичных отстойников, аэротенков и вторичных отстойников при проектировании комплексов по очистке сточных вод пока-

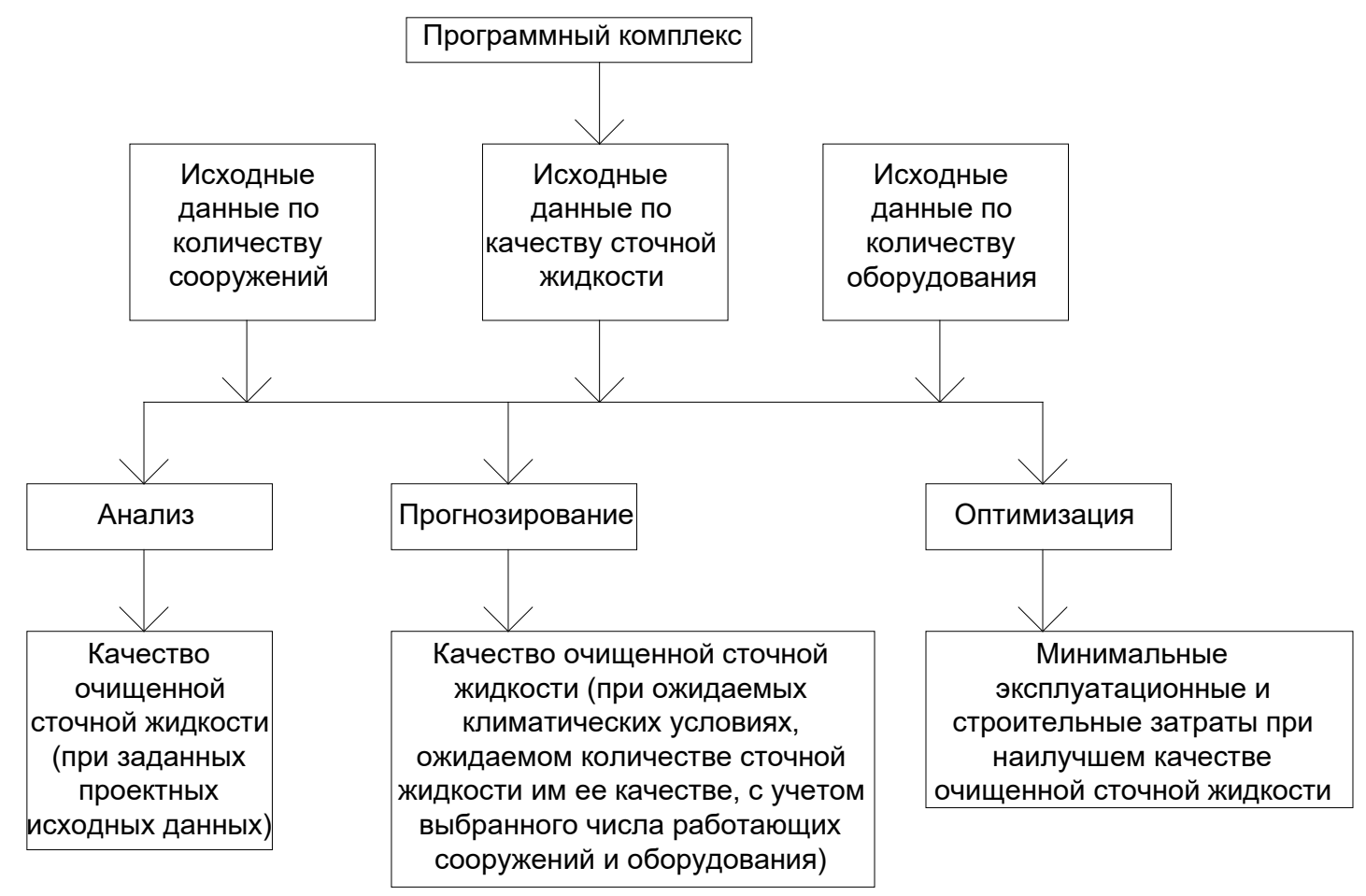

Рис. 3. Принципиальная схема работы программного комплекса 
зал, что при снижении температуры с 20 до $10^{\circ} \mathrm{C}$ качество сточной жидкости, прошедшей через эти сооружения, ухудшается.

Для изучения влияния климатических факторов на изменение температуры в открытых сооружениях (первичные и вторичные отстойники, аэротенк) был проведен сбор статистических данных за период с 2014 по 2019 г. и охватывает все сезоны года. Математическая обработка экспериментальных данных позволила получить функциональные зависимости, которые можно использовать для определения температуры сточной жидкости по ходу ее движения.

Анализ математических моделей тепломассообмена между сточной жидкостью открытых сооружений и окружающей средой позволил выявить основные статьи потерь и поступления тепла. К ним относятся: конвективный теплообмен, испарение с поверхности, потери тепла через ограждающие конструкции, излучение тепла с поверхности зеркала темного тела, унос и поступление тепла с воздухом, энергия солнца и тепло экзотермических реакций.

Результаты выполненной работы использованы для усовершенствования программного комплекса в помощь технологам очистных сооружений канализации, который учитывает изменение температуры сточной жидкости в ходе ее очистки.

\section{Литература}

1. Амбросова, Г. Т., Гвоздев, В. А., Меркель, О. М. и Бойко, Т. А. (2003). Существующие методы контроля работы очистных сооружений канализации. Изв. высш. учеб. заведений. Строительство, № 2 (530), сс. 86-90.

2. Амбросова, Г. Т., Кругликова, А. В., Мансуров, Р. Ш., Рафальская, Т. А. и Тимофеев, С. Л. (2019). Влияние природно-климатических факторов на эффективность работы открытых очистных сооружений канализации. Водоснабжение и санитарная техника, № 4, сc. 48-59.

3. Бартова, Л. В., Авдеева, М. А. и Луферчик, Я. С. (2018). Определение продолжительности обработки сточных вод в аэротенках по различным методикам. Вестн. ПНИПУ. Строительство и архитектура, Т. 9, № 3, сс. 99-107. DOI: $10.15593 / 2224-9826 / 2018.3 .10$.

4. Госстрой СССР (1986). СНиП 2.04.03-85. Канализация. Наружные сети и сооружения. М.: ЦИТП Госстроя СССР, 85 с.

5. Иткин, А. Л. (1970). К вопросу технологического моделирования процесса осветления сточных вод. В: Исследования по очистке сточных вод. Сборник трудов № 66 Московского инженерно-строительного института им. В. В. Куйбышева, сс. 92-99.
6. Калицун, В. И., Кедров, В. С., Ласков, Ю. М. и Сафонов, П. В. (1980). Гидравлика, водоснабжение и канализация. М.: Стройиздат, 359 с.

7. Министерство регионального развития Российской Федерации (2012). СП 131.13330.2012. Строительная климатология. Актуализированная редакция СНиП 23-01-99. М.: Минрегион России, 109 с.

8. Морозова, К. М. (2009). Принципы расчета систем биологической очистки сточных вод. Водоснабжение и санитарная техника, № 1, сс. 26-31.

9. Никитин,А.М.,Крыжановский,А.Н.,Амбросова, Г. Т., Быковский, О. В., Гвоздев, В. А. и Цветкова, О. П. (1999). Управление технологическими процессами на очистных сооружениях канализации. Водоснабжение и санитарная техника, № 3, сс. 39-40.

10. Шаптала, М. В. и Шаптала, Д. Е. (2014). Разработка математической модели процессов тепломассообмена открытого плавательного бассейна. Наука и прогресс транспорта. Вестн. Днепропетр. нац. ун-та ж.-д. транспорта, № 6 (54), cc. 113-118.

11. Эпов, А. Н. и Канунникова, М. А. (2016). Сравнение методик расчета сооружений с биологическим удалением азота и фосфора и применение математического моделирования. Вода и экология: проблемы и решения, № 1 (65), cc. 3-14.

12. Эпов, А. Н. и Канунникова, М. А. (2016). Сравнение методик расчета сооружений с биологическим удалением азота и фосфора и применение математического моделирования. Вода и экология: проблемы и решения, № 2 (66), cc. 65-80.

13. Яковлев, С. В. и Воронов, Ю. В. (2002). Водоотведение и очистка сточных вод. Учебник для вузов. 4-е изд. М.: Изд-во Ассоц. строит. вузов, 703 с.

14. Яковлев, С. В. и Карюхина, Т. А. (1980). Биохимические процессы в очистке сточных вод. М.: Стройиздат, $200 \mathrm{c}$.

15. Ambrosova, G. and Kruglikova, A. (2016). Effect of climatic conditions on the efficiency of work of open wastewater treatment plant. In: $8^{\text {th }}$ International Conference on Contemporary Problems of Architecture and Construction, October 26-28, 2016. Yerevan, National University of Architecture and Construction of Armenia, pp. 3-6.

16. Jones, R., Smith, C. C. and Löf, G. (1994). Measurement and analysis of evaporation from an inactive outdoor swimming pool. Solar Energy, Vol. 53, Issue 1, pp. 3-7. DOI: 10.1016/ S0038-092X(94)90597-5.

17. Köster, S. (2005). Bemessungsregeln für Nachklärbecken. Wasserwirtschaft, Wassertechnik : wwt ; Praxismagazin für Trink- und Abwassermanagement, No. 1-2, pp. 22-24.

18. Kruglikova, A. V. (2015). Impact of environment on sewage temperature in open sewage treatment facilities. In: Proceedings of the IWA $7^{\text {th }}$ Eastern European Young Water Professionals Conference, September 17-19, 2015. Belgrade, pp. 524-530.

\section{References}

1. Ambrosova, G. T., Gvozdev, V. A., Merkel, O. M. and Boyko, T. A. (2003). Existing methods of controlling 
the operation of sewage treatment facilities. News of Higher Educational Institutions. Construction, No. 2 (530), pp. 86-90.

2. Ambrosova, G. T., Kruglikova, A. V., Mansurov, R. Sh., Rafal'skaia, T. A. and Timofeev, S. L. (2019). Impact of natural and climatic factors on the efficiency of open wastewater treatment facilities operation. Water Supply and Sanitary Technique, No. 4, pp. 48-59.

3. Bartova, L. V., Avdeeva, M. A. and Luferchik, Ja. S. (2018). Determination of the duration of wastewater treatment in aerotanks by different methods. PNRPU Bulletin. Construction and Architecture, Vol. 9, No. 3, pp. 99-107. DOI: 10.15593/2224-9826/2018.3.10.

4. Gosstroy of the USSR (1986). Construction Rules and Regulations SNiP 2.04.03-85. Public Sewer Systems and Facilities. Moscow: Central Institute of Standard Designing, Gosstroy of the USSR, $85 \mathrm{p}$.

5. Itkin, A. L. (1970). Revisiting the process simulation of wastewater clarification. In: Studies on wastewater treatment. Proceedings No. 66 of the Kuibyshev Moscow Institute of Civil Engineering, pp. 92-99.

6. Ministry of Regional Development of the Russian Federation (2012). Set of Rules SP 131.13330.2012. Building climatology. Revised edition of Construction Rules and Regulations SNiP 23-01-99. Moscow: Ministry of Regional Development of the Russian Federation, 109 p.

7. Kalitsun, V. I., Kedrov, V. S., Laskov, Yu. M. and Safonov, P. V. (1980). Hydraulics, water supply and sewerage. Moscow: Stroyizdat, $359 \mathrm{p}$

8. Morozova, K. M. (2009). Principles of calculation of biological wastewater treatment systems. Water Supply and Sanitary Technique, No. 1, pp. 26-31.

9. Nikitin, A. M., Krizhanovsky, A. N., Ambrosova, G. T., Bykovsky, O. V., Gvozdev, V. A. and Tsvetkova, O. P. (1999). Management of technological processes at wastewater treatment facilities. Water Supply and Sanitary Technique, No. 3, pp. 39-40.

10. Shaptala, M. V. and Shaptala, D. E. (2014). Mathematical model development of heat and mass exchange processes in the outdoor swimming pool. Science and Transport Progress. Bulletin of Dnipropetrovsk National University of Railway Transport, No. 6 (54), pp. 113-118.

11. Epov,A. N. and Kanunnikova, M.A. (2016). Comparison of structural analysis methods of nitrogen/phosphorus biological removal plants with mathematical modeling application. Water and Ecology, No. 1 (65), pp. 3-14.
12. Epov, A. N. and Kanunnikova, M.A. (2016). Comparison of structural analysis methods of nitrogen/phosphorus biological removal plants with mathematical modeling application. Water and Ecology, No. 2 (66), pp. 65-80.

13. Yakovlev, S. V. and Voronov, Yu. V. (2002). Wastewater disposal and treatment. Textbook for higher educational institutions. $4^{\text {th }}$ edition. Moscow: ASV Publishing House, 703 p.

14. Yakovlev, S. V. and Karyukhina, T. A (1980). Biochemical processes in wastewater treatment. Moscow: Stroyizdat, $200 \mathrm{p}$.

15. Ambrosova, G. and Kruglikova, A. (2016). Effect of climatic conditions on the efficiency of work of open wastewater treatment plant. In: $8^{\text {th }}$ International Conference on Contemporary Problems of Architecture and Construction, October 26-28, 2016. Yerevan, National University of Architecture and Construction of Armenia, pp. 3-6.

16. Jones, R., Smith, C. C. and Löf, G. (1994). Measurement and analysis of evaporation from an inactive outdoor swimming pool. Solar Energy, Vol. 53, Issue 1, pp. 3-7. DOI: 10.1016/ S0038-092X(94)90597-5.

17. Köster, S. (2005). Bemessungsregeln für Nachklärbecken. Wasserwirtschaft, Wassertechnik : wwt ; Praxismagazin für Trink- und Abwassermanagement, No. 1-2, pp. 22-24.

18. Kruglikova, A. V. (2015). Impact of environment on sewage temperature in open sewage treatment facilities. In: Proceedings of the IWA $7^{\text {th }}$ Eastern European Young Water Professionals Conference, September 17-19, 2015. Belgrade, pp. 524-530.

\section{Автор}

Кругликова Анастасия Валерьевна, аспирант, старший преподаватель

Новосибирский государственный архитектурностроительный университет (Сибстрин), Новосибирск, Россия

E-mail: nastikrug@mail.ru

Kruglikova Anastasiia Valerevna, Post-graduate Student, Chief lecturer

Novosibirsk State University of Architecture and Civil Engineering, Novosibirsk, Russia

E-mail: nastikrug@mail.ru 